\title{
DISEQUILIBRIUM GROWTH THEORY
}

by

Takatoshi Ito

Discussion Paper No. 79 - 113, September 1979

\author{
Center for Economic Research \\ Department of Economics \\ University of Minnesota \\ Minneapolis, Minnesota 55455
}


DISEQUILIBRIUM GROWTH THEORY

\section{Abstract}

This paper is an attempt to extend an analysis of disequilibrium macroeconomics to a problem of capital accumulation. The real wage is assumed to be sluggish so that the labor market may be in disequilibrium. The transaction of labor takes place at the minimum of supply and demand. The interaction between wage adjustment and capital accumulation is studied. If wage adjustment is slow, and if the saving rate from profits is larger than that from wages, then an endogenous force of business cycles switching between unemployment and overemployment regimes can be demonstrated. An appendix to this paper shows a sufficient condition for the stability of differential equation systems in a two-dimensional Euclidean space with switching regimes. This is a mathematical contribution which bears an independent interest.

Takatoshi Ito

Department of Economics University of Minnesota 1035 Business Administration Minneapolis, MN 55455 


\section{DISEQUILIBRIUM GROWTH THEORY *}

Takatoshi ITO

\section{Introduction}

Disequilibrium macroeconomics has been one of the active areas of research for the last ten years. After Clower (1965) and Leijonhufvud (1968) proposed a new definition of the effective demand, Barro and Grossman(1971, 1976), Malinvaud (1977), Hildenbrand and Hildenbrand (1978), and Muellbauer and Portes (1978) showed a static quantityconstrained equilibria for simple macroeconomic models. In these models the price and the wage are rigid, therefore the aggregate demand is not necessarily equal to the aggregate supply for a market. The economy is classified into four regimes according to the excess demands and supplies in both the aggregate consumption good and the labor markets. A notable result in these literature is that comparative statics of an economy are radically different for a different regime where the economy stays.

As for dynamics, depending on the direction and size of disequilibrium of a market, a price adjustment scheme over time is defined. Böhm (1978) and Honkapohja $(1978,1979)$ showed a dynamic path of static quantityconstrained equilibria. However, these models do not incorporate endogenous capital accumulations.

\footnotetext{
* This work is based on a part of my Ph.D. dissertation (Harvard University, 1979) and has benefited from comments from Kenneth Arrow, Jerry Green, Olivier Blanchard and Benjamin Friedman. I am also grateful to Walter $\mathrm{P}$. Heller and anonymous referees for helpful criticisms. Financial support from NSF Grant SOC78-06162 is gratefully acknowledged.
} 
In this paper, I shall introduce capital accumulations into a dis'equilibrium macroeconomic model, where increase in capital stock is determined by the saving decision of households, like neoclassical growth theory.

Growth theory with unemployment as a quantity constraint makes it possible to investigate problems such as business cycles switching regimes of unemployment and overemplojment, and unemployment caused by a spurt of technological progress which replaces the labor force.

I develop disequilibrium growth theory as follows: I take a onesector neoclassical growth model, ' but do not assume perfect flexibility of the wage. If the wage is fixed at the moment (or for a certain period) by an invisible auctioneer with lagged information or by the visible government, then the labor market is under a regime of excess supply (unemployment), excess demand (overemployment), or (exact) full employment. The actual transactions are assumed to take place at the minimum of demand and supply of labor force. In the regime of unemployment, workers cannot satisfy their notional wage incomes, while in the overemployment regime, owners of firms cannot fulfill their notional plans of production and profit. Therefore, the amount of saving depends on not only the wage rate but also under which regime the labor market operates. The amount of saving determines a path of capital accumulation, white the wage rate may be partially adjusted according to the regime of 
the labor market. Movements of capital per capita and the wage rate will trace a disequilibrium path of a growing economy.

We will face the question of the stability of differential equation systems with switching regimes, each regime being associated with a different set of differential equations. This kind of "patched-up" system of differential equations has not been investigated. We will give a simple condition for local stability of a two-dimensional patchedup system.

To sum up, a framework to deal with capital accumulation is inherited from neoclassical growth theory, while the short-run rigidity of prices and the minimum transaction rule of demand and supply in nonmarket-clearing prices are adopted from disequilibrium macroeconomics. Therefore the present model is differentiated from the earlier models of "disequilibrium growth" or "unemployment in a theory of growth."."

I demonstrated the above idea in a special example in Ito (1978), where the Diamond model (1965) of overlapping generations was chosen for the framework. Since I employed in my note the Cobb-Douglas functions for utility and production and optimistic expectations about the future, the model implied that workers (i.e., the young generation) save a constant fraction of their realized income. Moreover, the two-period overlapping generations model without bequests implies that capitalists (i.e., the older generation) never save. It would be most desirable to generalize the Diamond model to the n-period overlapping generations model with a general utility and production function. However, it would 
be extremely difficult. Instead, I adopt a neoclassical model where the saving rates from the wage income and from the profit income are different. 3

In the next section, I shall describe the model. In Section 3, I shall examine the stability of the model over time. It will be shown that a disequilibrium dynamic path fluctuates between the unemployment and overemployment regimes, exploding away or converging to the neoclassical long-run steady state. I shall prove a new theorem on the stability of a dynamic path with switching regimes. An alternative wage adjustment scheme is examined in Section 4 . Section 5 will be devoted to the study of the implications of the results obtained in the earlier sections, including business cycles and technological unemployment, and concluding remarks are given in Section 6 .

\section{The Model}

\subsection{Framework}

The (flow of) output at time $t, Y_{t}$ ', is determined by the (flow of) labor force at time $t, L_{t}$, and the (stock of) capital, $k_{t}$. The production function, $F$, is assumed to be twice differentiable and homogeneous of degree one, i.e.,

$$
Y_{t}=F\left(K_{t}, L_{t}\right) \quad \text { for } K_{t} \geq 0, L_{t} \geq 0
$$

and

$$
\lambda F\left(K_{t}, L_{t}\right)=F\left(\lambda K_{t}, \lambda L_{t}\right) \text { for } \lambda>0 \text {. }
$$


We can write the production functions in the intensive form due to the homogeneity assumption:

$$
Y_{t} / L_{t}=f\left(K_{t} / L_{t}\right)
$$

Assume that the production function is "well-behaved":

$$
f(0)=0
$$

$$
\begin{aligned}
& f^{\prime}(\cdot)>0 \text { and } f^{\prime \prime}(\cdot)<0 \\
& \lim _{K / L \rightarrow 0} f^{\prime}(\cdot)=\infty \text { and } \lim _{K / L \rightarrow \infty} f^{\prime}(\cdot)=0 \text {. }
\end{aligned}
$$

At each moment of time, the capital stock is historically given and the wage rate is also fixed. The (representative) firm maximizes the (flow of) profit, $\Pi_{t}$, with respect to the labor input.

$$
\operatorname{Max}_{t} \Pi_{t} \equiv Y_{t}-w_{t} L_{t}
$$

The labor demand, $L^{d}$, is the level of labor input which satisfies

$$
w_{t}=F_{L}\left(K_{t}, L_{t}\right)
$$

where $F_{L} \equiv \partial F / \partial L$. Since $F$ is homogeneous of degree one, $F_{L}$ is homogeneous of degree zero. Therefore, we have a separable form:

$$
L_{t}^{d}=\Omega\left(w_{t}\right) \cdot K_{t} \quad \Omega^{\prime}<0
$$

I assume, for the sake of simplicity, that the labor supply per capita, $\ell$, is inelastic. ${ }^{4}$ Therefore, the aggregate labor supply, $L^{5}$, is

$$
L_{t}^{s}=\ell N_{t}
$$


where $N_{t}$ is the population. The transaction rule in disequilibrium is the usual minimum of demand and supply

$$
L_{t}=\min \left[L_{t}^{d}, L_{t}^{s}\right]
$$

I here introduce several notations for convenience. First, let us define capital per capita by $k_{t} \equiv k_{t} / N_{t}$. Note that this variable does not depend on the current wage rate or the actual level of employment. Secondly, I set $\ell=1$ by choosing an appropriate unit of measurement. Thirdly, I introduce the desired capital/labor ratio, $k_{t}^{d} \equiv k_{t} / L_{t}^{d}=1 / \Omega\left(w_{t}\right)$. This variable is a function of the current wage rate, although capital per capita is not. Using (2.3) and the Euler equation for a homogeneous function, we have:

$$
w_{t}=f\left(k_{t}^{d}\right)-k_{t}^{d} f^{\prime}\left(k_{t}^{d}\right)
$$

I shall describe this economy by two state variables, $k_{t}$ and $w_{t}$. Keep in mind the following discussion that $k_{t}^{d}$ does not depend on $k_{t}$ but on $w_{t}$.

There are three possible regimes in the labor market. The labor market is under full-employment, unemployment and overemployment, if $L^{d}=L^{s}, L^{d}<L^{s}$ and $L^{s}<L^{d}$, respectively.

It is easy to see the following relations:

$$
\frac{k_{t}}{L_{t}}=k^{d}\left(w_{t}\right)
$$

in the full employment and unemployment regimes;

and

$$
\frac{k_{t}}{L_{t}}=k_{t}
$$

in the full employment and overemployment regimes. 
Hereafter I omit the subscript $t$, when it is possible. Capital accumulation is solely determined by the savings decision as in a neoclassical growth model. In the Kaldor (1960) model, the increase (flow) of capital is the sum of workers' saving and capitalists' saving:

$$
\begin{aligned}
\dot{K} & =s_{W} w L+s_{K}(Y-w L) \\
& =s_{K} F(K, L)+\left(s_{W}-s_{K}\right) w L \\
& =s_{K} L f(K / L)+\left(s_{W}-s_{K}\right) w L,
\end{aligned}
$$

where $\dot{K}=d K / d t, 0<s_{w}<1$, and $0<s_{K}<1$. I assume that those saving rates as constants.

One of the characteristics of the disequilibrium growth model is that the capital accumulation equation, (2.10), is different for each regime. This is clear from the relations (2.8) and (2.9).

The population is assumed to grow at a constant rate, $n$, i.e., $\dot{N} / N=n$. Since there are only two commodities in an economy, I can take the price of output as numeraire. Moreover, the demand and supply for output is always balanced, because output which is not consumed becomes saving which is equivalent to investment. Let us now consider the wage adjustment equation.

First, I take a simple scheme of wage adjustment. Assume the law of supply and demand, i.e., the wage increases in the overemployment regime and goes down in the unemployment regime. Moreover, the wage adjustment is assumed to be proportional to the rate of unemployment or overemployment, but the proportion may be different in the positive direction or the negative direction. 


$$
\dot{w}=\begin{array}{ll}
\xi_{1} \frac{L^{d}-L^{s}}{L^{s}} & \text { if } L^{d} \geq L^{s}, \xi_{1}>0, \\
\xi_{2} \frac{L^{d}-L^{s}}{L^{s}} & \text { if } L^{d}<L^{s}, \xi_{2}>0,
\end{array}
$$

or rewriting this using the established notation

$$
\begin{aligned}
\dot{w}=\xi\left(\frac{k}{k^{d}(w)}-1\right) \quad \xi & =\xi_{1} \text { if } L^{s} \leq L^{d} \\
\xi & =\xi_{2} \text { if } L^{d}>L^{s} .
\end{aligned}
$$

We will see that the above equation does not maintain full employment unless the economy is in the steady state. We may want to use a wage adjustment scheme which would keep the economy on the neoclassical path once it has been attained. Therefore wage adjustment consists of the effect of a change in productivity and the effect of disequilibrium:

$$
\begin{aligned}
\dot{w}=-f^{\prime \prime}(k) k \dot{k}+\xi\left(k / k^{d}(w)-1\right), \quad \xi & =\xi_{1} \quad \text { if } L^{s} \leq L^{d} \\
\xi & =\xi_{2} \quad \text { if } \quad L^{s}>L^{d} .
\end{aligned}
$$

I shall contrast (2.11) and (2.12) in the following subsections.

\subsection{Full Employment Regime}

First, I shall start by examining a regime where the current combination of the capital per capita and the wage rate gives a state of full employment. That is, from (2.4), (2.5) and $\ell \equiv 1$,

$$
\Omega\left(w_{t}\right) K_{t}=N_{t} \text {, for all } t \text {. }
$$


Solving this equation for $w_{t}$, we have "the full employment wage rate" denoted by $w^{*}$, depending on the capital per capita:

$$
w_{t}^{*}=n\left(k_{t}\right)
$$

Since $k_{t}=k^{d}\left(w_{t}\right)$ in the full employment regime, we know by (2.7),

$$
w_{t}^{*}=n\left(k_{t}\right)=f\left(k_{t}\right)-k_{t} f^{\prime}\left(k_{t}\right) \text {. }
$$

In other words, the full employment regime is defined as a set $R_{f}=\mathbb{R}_{+}^{2}$

$$
R_{f}=\left\{(k, w) \varepsilon \mathbb{R}_{+}^{2} \mid w=f(k)-k f^{\prime}(k)\right\} .
$$

We know that the full employment wage rate is an increasing function with respect to the capital per capita, because of Assumption (2.2).

$$
\frac{d w^{*}}{d k}=\eta^{\prime}(k)=-k f^{\prime \prime}(k)>0 \text {. }
$$

Since the full employment wage rate is a function of the capital per capita, we have a dynamic equation of capital accumulation per capita, substituting (2.9) and (2.13) into (2.10):

$$
\begin{aligned}
\dot{k} & \equiv k(\dot{K} / K-\dot{N} / N) \\
& =s_{w} f(k)-\left(s_{w}-s_{K}\right) k f^{\prime}(k)-n k
\end{aligned}
$$

Note that the increase in capital per capita does not depend on the wage rate any more. Since the labor market is in equilibrium, the wage rate does not change. 
( $F$

$$
\begin{aligned}
& \dot{k}_{t}=s_{w} f\left(k_{t}\right)-\left(s_{w}-s_{k}\right) k_{t} f^{\prime}\left(k_{t}\right)-n k_{t}, \\
& \dot{w}_{t}=0 .
\end{aligned}
$$$$
\text { for }\left(k_{t}, w_{t}\right) \in R_{f}
$$

The dynamic equations of (F) imply that $\left(k_{t}, w_{t}\right)$ will not be in (F) at the next moment unless $k_{t}$ is a special value so that $\dot{k}=0$. It is heuristically interesting to consider the neoclassical model in our framework. Full employment is assumed over time in the neoclassical models by instantaneous adjustment of the wage rate. Therefore the dynamic equation of the neoclassical model is equation (2.15) only.

$$
\dot{k}_{t}=s_{w} f\left(k_{t}\right)-\left(s_{w}-s_{k}\right) k_{t} f^{\prime}\left(k_{t}\right)-n k_{t} \text {, for all } k_{t}>0 \text {. }
$$

The wage rate is adjusted solely according to labor productivity:

$$
w_{t}=f\left(k_{t}\right)-k_{t} f^{\prime}\left(k_{t}\right)
$$

This wage rate is guaranteed to be achieved if the wage is adjusted according to (2.12) and the initial state is one of full employment.

In the next two sections, I assume that wage adjustment follows (2.11). In Section 4, I shall come back to the implications of wage adjustment according to (2.12).

I introduce a notion of "neoclassical steady state,": output and inputs are growing at the same rate, or the natural rate, $n$. Let us denote the steady state capital per capita by $\hat{k}$ and the associated wage rate by $\hat{w}$. Then

$$
\begin{aligned}
& \hat{k}=\left\{k / s_{w} f(k)-\left(s_{w}-s_{k}\right) k f^{\prime}(k)-n k=0\right\} \\
& \hat{w}=f(\hat{k})-\hat{k} f^{\prime}(\hat{k}) .
\end{aligned}
$$


Note that $\hat{k}$ gives the steady state to system (F), too.

We know that a neoclassical growth model is globally stable under plausible assumptions. Our concern here is how the conclusion may change when we allow short-run disequilibria. I shall take for granted the stability of the neoclassical model. It is well known that the Kaldor hypothesis, i.e., $s_{K} \geq s_{W}$, is a sufficient condition of stability in the two-class model. I, however, am also interested in a case of $s_{W}>s_{K}$ which is implied by the life-cycle hypothesis. I introduce the elasticity of substitution, $\sigma$, of the production function:

$$
\sigma \equiv d \log (K / L) / d \log \left(F_{L} / F_{K}\right)
$$

It is easy to verify that $\sigma$ is described in terms of the intensive form: 5

$$
\sigma=-\frac{f^{\prime}(k)\left\{f(k)-k f^{\prime}(k)\right\}}{k f(k) f^{\prime \prime}(k)}>0 .
$$

The sign comes from Assumption (2.2).

Theorem 2.1: The neoclassical model is defined by (2.1), (2.2), and $(N)$. There exists a unique equilibrium (steady state) value of the capital per capita, and it is globally asymptotically stable, if

$$
\sigma>\left(1-\frac{s_{K}}{s_{w}}\right) \frac{k f^{\prime}(k)}{f(k)} \quad \text { for all } k>0 \text {. }
$$

A proof is given in Appendix 1.

Remark 1: Equation (2.19) is satisfied if $s_{K} \geq s_{W}$, that is the original Kaldor hypothesis, since the RHS $\leq 0$ and $\sigma>0$. 
Remark 2: Equation (2.19) is satisfied if the production function is of the Cobb-Douglas type, $f(k)=A k^{\beta}$, even if $s_{W}>s_{K}$. Since $k f^{\prime}(k) / f(k)=B<1$ and $\left\{1-\left(s_{K} / s_{W}\right)\right\}<1$, the RHS $<1$. It is easy to see that $\sigma=1$ for a Cobb-Douglas production function, therefore the LHS $=1$.

Remark 3: With the same logic, (2.19) is satisfied when we have any production function with the elasticity of substitution greater than one for $k>0$, in addition to Assumption (2.2).

Remark 4: The above remarks imply that the only chance that the neoclassical model is unstable is in a case where $\sigma$ is sufficiently less than 1 and $s_{W}>s_{K}$. It is a well-known proposition that $\sigma<1$ implies the wage share $\left\{f(k)-f^{\prime}(k) k\right\} / f(k)$ increases as $k$ increases. Since the saving rate from wage income is larger, it is plausible that $\dot{k}$ increases as $k$ increases. This means the steady state is unstable.

In the following we assume (2.19). Now let us go back to the full employment regime of the disequilibrium model. From (2.15) and (2.16), we have the following sign condition

$$
\begin{array}{llll}
\dot{k}<0, & \dot{w}=0 & \text { if } & \hat{k}<k,(k, w) \varepsilon R_{f} \\
\dot{k}=0, \dot{w}=0 & \text { if } & k=\hat{k},(k, w) \varepsilon R_{f} \\
\dot{k}>0, \dot{w}=0 & \text { if } & k<\hat{k},(k, w) \varepsilon R_{f} .
\end{array}
$$




\subsection{Unemployment Regime}

We now turn to the unemployment regime. The current wage rate is higher than the full employment wage rate, $w^{*}=n\left(k_{t}\right)$, therefore $L^{d}<L^{s}$. The unemployment regime set in the $(k, w)$ plane is denoted as $R_{u}$,

$$
R_{u}=\left\{(k, w) \varepsilon \mathbb{R}_{+}^{2} \mid w>f(k)-k f^{\prime}(k)\right\} .
$$

Since the firm's demand for labor is satisfied, the marginal condition (2.3) is attained. In other words, the capital-employment ratio is determined by (2.8), and equal to the desired capital-labor ratio, $k^{d}(w)$ :

$$
w_{t}=f\left(k^{d}\left(w_{t}\right)\right)-k^{d}\left(w_{t}\right) f^{\prime}\left(k^{d}\left(w_{t}\right)\right) .
$$

Using (2.20), the rate of capital accumulation is simplified as follows:

$$
\begin{aligned}
\frac{\dot{k}}{k} & =s_{K} \frac{f\left(k^{d}\right)}{k^{d}}+\left(s_{w}-s_{K}\right) \frac{w_{t}}{k^{d}} \\
& =s_{w} f\left(k^{d}\right) / k^{d}+\left(s_{K}-s_{w}\right) f^{\prime}\left(k^{d}\right) .
\end{aligned}
$$

Therefore

$$
\dot{k}_{t}=k_{t}\left[s_{w} f\left(k^{d}\left(w_{t}\right)\right) / k^{d}\left(w_{t}\right)+\left(s_{k}-s_{w}\right) f^{\prime}\left(k^{d}\left(w_{t}\right)\right)-n\right] .
$$

Let us denote $[\cdot]$ in $(2.22)$ by $h\left(w_{t}\right)$. Note that $\dot{k} \geq 0$ as $h\left(w_{t}\right) \geq 0$, respectively. However, $h\left(w_{t}\right)$ is independent of $k_{t}$. This results from the homogeneous production function. Since labor demand is multiplicatively separable with respect to the wage rate and the total capital 
stock, the capital per employee is independent of the total capital stock. Only the ratio between the capital stock and employment matters.

For the dynamic equation of the wage rate, assume (2.11). Therefore (2.11) and (2.22) give a system of equations which describes the motion in the $R_{u}$ and its boundary $R_{f}$.

$$
\dot{k}_{t}=k_{t} h\left(w_{t}\right)
$$

$$
\dot{w}_{t}=\xi_{2}\left\{k_{t} / k^{d}\left(w_{t}\right)-1\right\}, \text { for }\left(k_{t}, w_{t}\right) \in R_{u} \cup R_{f} \text {. }
$$

Note that (U) coincides with $(F)$ at $(k, w) \varepsilon R_{f}$. Now we check the sign of $\dot{k}$ in the unemployment regime. First note that $\dot{k}_{t}=0$ at $(\hat{k}, \hat{w})$. Secondly,

$$
\left.\frac{d w}{d k}\right|_{\substack{k, w) \varepsilon R_{u} \\ k=0}}=-\left.\frac{\partial \dot{k} / \partial k}{\partial \dot{k} / \partial w}\right|_{\substack{(k, w) \varepsilon R_{u} \\ k=0}}=0 \text {, }
$$

since $k\left(w_{t}\right)$ in equation $(2.22)$ is independent of $k_{t}$. Thirdly

$$
\begin{aligned}
\frac{\partial \dot{k}}{\partial w}= & k \frac{d h}{d k^{d}} \frac{d k^{d}}{d w} \\
= & -k_{t^{2}}\left[s_{w^{\prime}}\left\{k^{d} f^{\prime}\left(k^{d}\right)-f\left(k^{d}\right)-\left(k^{d}\right)^{2} f^{\prime \prime}\left(k^{d}\right)\right\} /\left(k^{d}\right)^{2}\right. \\
& \left.+s_{k^{\prime \prime}} f^{\prime \prime}\left(k^{d}\right)\right] / k^{d} f^{\prime \prime}\left(k^{d}\right),
\end{aligned}
$$

where $[\cdot]<0$ if condition (2.19) is satisfied, by the same argument in the proof of Theorem 2.1. Therefore: 


$$
\begin{array}{llll}
\dot{k}_{t}<0, & \dot{w}_{t}<0 & \text { if } & \hat{w}<w_{t},\left(k_{t}, w_{t}\right) \varepsilon R_{u} \\
\dot{k}_{t}=0, \dot{w}_{t}<0 & \text { if } & w_{t}=\hat{w},\left(k_{t}, w_{t}\right) \varepsilon R_{u} \\
\dot{k}_{t}>0, \dot{w}_{t}<0 & \text { if } & w_{t}<\hat{w},\left(k_{t}, w_{t}\right) \varepsilon R_{u}
\end{array}
$$

gives the signs of paths of the state variables.

\subsection{Overemployment Regime}

Lastly, let us examine the case of the overemployment regime,

where $L^{s}<L^{d}$, or equivalently $w_{t}<w^{*}=n(k)$. A set of the state variables, $(k, w)$, which gives the overemployment regime is denoted by $R_{0}$,

$$
\text { - } R_{0}=\left\{(k, w) \varepsilon \mathbb{R}_{+}^{2} \mid w<f(k)-k f^{\prime}(k)\right\} .
$$

Since actual employment is determined by the supply side, substitute (2.9) into (2.10) to obtain the following equation:

$$
\frac{\dot{k}}{k}=\frac{s_{K} f\left(k_{t}\right)}{k_{t}}+\left(s_{w}-s_{k}\right) \frac{w_{t}}{k_{t}} \text {, }
$$

or in terms of the intensive form:

$$
\dot{k}=s_{K} f\left(k_{t}\right)+\left(s_{w}-s_{K}\right) w_{t}-n k_{t} \text {. }
$$

Since the demand for labor is quantity-constrained, the marginal condition of (2.3) is not satisfied. That is $w_{t} \neq f\left(k_{t}\right)-k f^{\prime}\left(k_{t}\right)$. Take equation (2.11) as the wage adjustment mechanism in the overemployment regime. Therefore (2.11) and (2.23) give a system of equations which describes the motion in the $R_{0}$ and its boundary $R_{f}$. 


$$
\dot{k}_{t}=s_{K} f\left(k_{t}\right)+\left(s_{w}-s_{K}\right) w_{t}-n k_{t}
$$

(0)

$$
\dot{w}_{t}=\xi_{j}\left\{k_{t} / k^{d}\left(w_{t}\right)-1\right\} \text {, for }\left(k_{t}, w_{t}\right) \in R_{0} \cup R_{f} \text {. }
$$

Note that (0) coincides with $(F)$ at $(k, w) \in R_{f}$. Next we check the signs of the time derivatives. First, from (2.23) we know that $\dot{k} \geq 0$ iff $s_{K} f(k)+\left(s_{K}-s_{W}\right) w-n k \geq 0$ respectively. Define the wage rate which gives the stationary movement of $k$ in the overemployment regime, as:

$$
\left\{\begin{array}{lll}
\phi(k)=\left\{n k-s_{K} f(k)\right\} /\left(s_{W}-s_{K}\right), & s_{W} \neq s_{K} \\
\phi & =\hat{k}, & s_{W}=s_{K} .
\end{array}\right.
$$

Then

$$
\begin{array}{llcl}
\dot{k}_{t}=0, \dot{w}_{t}>0 & \text { iff } \quad w_{t}=\phi\left(k_{t}\right) ; \\
\dot{k}_{t}>0, \dot{w}_{t}>0 & \text { if } & \left\{w_{t}-\phi\left(k_{t}\right)\right\}\left\{s_{w}-s_{K}\right\}>0, s_{w} \neq s_{K}
\end{array}
$$

$$
\begin{array}{ll} 
& \text { or if } k_{t}<\hat{k}, s_{w}=s_{K} ; \\
\dot{k}_{t}<0, \dot{w}_{t}>0 \quad \text { if } \quad\left\{w_{t}-\phi\left(k_{t}\right)\right\}\left\{s_{w}-s_{K}\right\}<0, s_{w} \neq s_{K} \\
& \text { or if } k_{t}>\hat{k}, s_{w}=s_{K} ;
\end{array}
$$

for $\left(k_{t}, w_{t}\right) \in R_{0}$.

A careful examination of the relative positions of $n(k)$, the full employment wage rate, and $\phi(k)$ shows that 
if $s_{K}<s_{W}$, then $\phi(k) \leq n(k)$ for $k \leq \hat{k}$, respectively and $\phi^{\prime}(k)>0$;

$$
\begin{gathered}
\text { if } s_{w}<s_{k} \text {, then } \phi(k) \leq n(k) \text { for } \hat{k} \leq k \text {, respectively, } \\
\text { and } \phi^{\prime}(k)<0 .
\end{gathered}
$$

(See Appendix 2 for the derivation.) Now we are ready to draw a phase diagram for a disequilibrium system, which consists of $(U),(F)$, and (0) for $(k, w) \varepsilon \mathbb{R}_{+^{\circ}}^{2}$ By combining (FS), (US), (OS), (2.13), (2.16), $(2.17),(2.24),(2.25)$ and $(2.26)$, we have Figures $V .1$ and $V .2$ for the cases of $s_{K}<s_{W}$ and $s_{W}<s_{K}$, respectively. If $s_{K}=s_{W}$, then $\phi(k)$ is vertical at $k=\hat{k}$.

The full employment regime is described by a curve $n(k)$ in Figures 1 and 2. The neoclassical growth model, $(N)$, is a special case here in that it is restricted to the curve $n(k)$. The unemployment regime is anywhere above. the curve, and the overemployment regime is anywhere below the curve. The dotted curves are a combination of $(k, w)$ which gives $\dot{k}=0$.

In the following sections, I shall examine the stability of the disequilibrium system of $(U),(F)$ and $(0)$, and discuss the implications of the model.

Figures 1 and 2 about here 
$-17 a-$

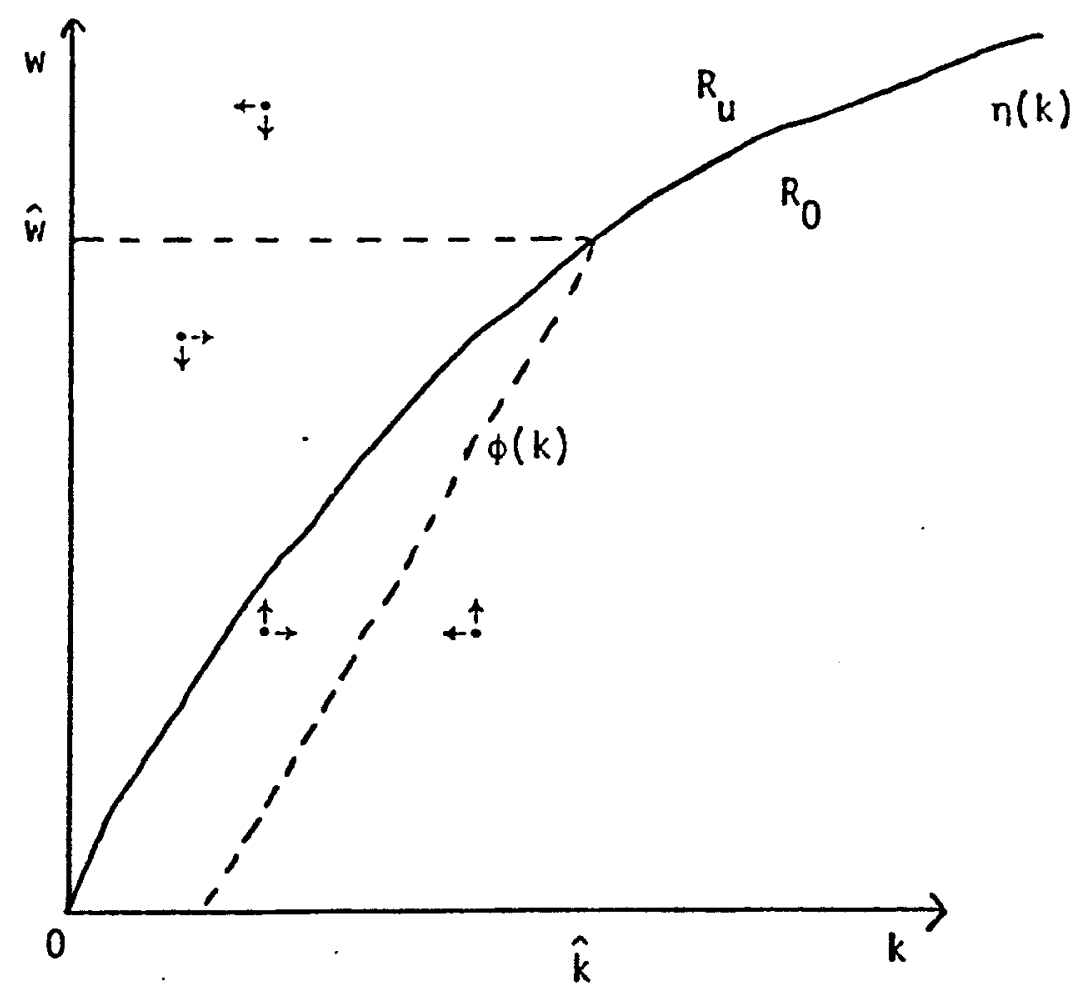

FIGURE I

$$
s_{W}>s_{K}
$$

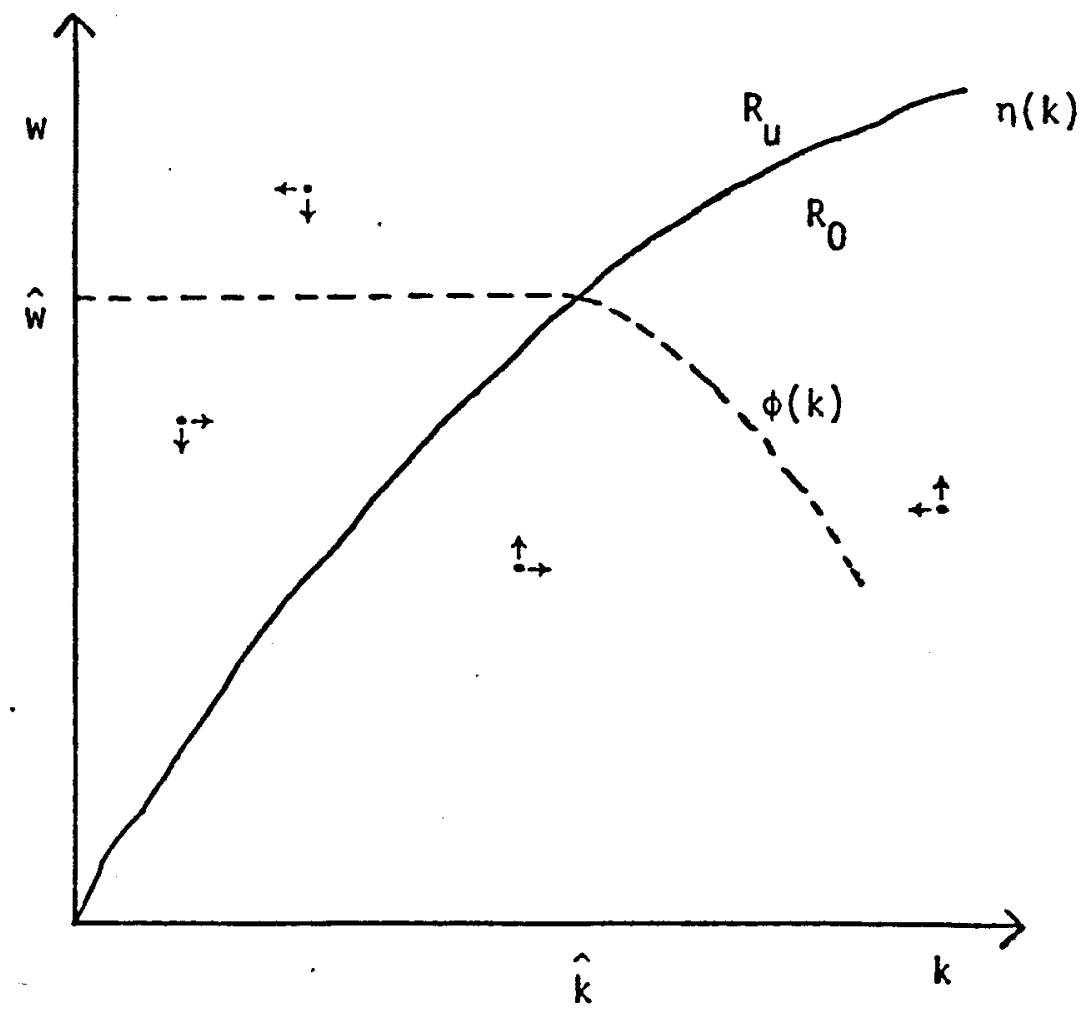

Figure 2

$$
s_{W}<s_{K}
$$




\section{Stability}

We have started with the question of how a model changes when we allow disequilibria while the equilibrium (neoclassical) path exhibits global stability to the long-run steady state, $\hat{k}$. We are now ready to answer the above question. Our disequilibrium system consists of two different sets of differential equations, (U) and (0). They give the same values at their common boundary, (F). Since the domain is divided into two different regions, the usual theorems of local or global stability cannot be applied without modification and restriction. Especially note that global stability in each set of differential equations (assuming it is defined for $\mathbb{R}_{+}^{2}$ ) does not guarantee global stability of a "patched-up" system. ${ }^{6}$ However, it is possible to assert global, and therefore local, stability in the case of $s_{K}<s_{W}$, by just looking at Figure 1 . Notice that in the region between $n(k)$ and $\phi(k): k<\hat{k}$ "locks in" the solution path, once it comes in the region. Since $\dot{k} \rightarrow 0$ as $k \rightarrow 0$, a solution path never hits the vertical axis even if $w>\hat{w}$. It is clear from the diagrams that a solution path does not approach the horizontal axis. Therefore a solution path has to converge to the steady state eventually. The cases can be extended to the special case of $s_{K}=s_{W}$.

Therefore we have the following theorem.

Theorem 3.1: In the case of $s_{K} \leq s_{W}$, a disequilibrium system of (U) and (0) has the unique steady state $(\hat{k}, \hat{w})$ and it is globally asymptotically stable. 
In the case of $s_{W}<s_{K}$, it is a complicated matter to establish local stability. Moreover, global stability is not guaranteed. First, I prove that for local stability of a patched-up system, (U) and (0), it is sufficient to prove local stability for each of $(U)$ and $(0)$ around the steady state point, given that the boundary can be linearly approximated. 7

Theorem 3.2: In the case of $s_{W}<s_{K}$ a disequilibrium system defined by $(U)$ and $(0)$ is locally stable at $(\hat{k}, \hat{w})$, in the sense that $\exists \delta>0$, such that

$$
\lim _{t \rightarrow \infty}\left(k_{t}, w_{t} \mid\left(k_{0}, w_{0}\right)\right)=(\hat{k}, \hat{w}) \text {, if }\left\|\left(k_{0}, w_{0}\right)-(\hat{k}, \hat{w})\right\|<\delta .
$$

A proof is given in Appendix 3.

\section{Alternative Wage Adjustment}

I showed an alternative wage adjustment scheme, (2.12), which consists of the productivity effect and the disequilibrium effect. Then the wage adjustment equations for the regimes $(F),(U)$, and (0) are given by $(4.1),(4.2)$, and $(4.3)$, respectively.

$$
\begin{aligned}
& \dot{w}=-f^{\prime \prime} k \dot{k} \\
& \dot{w}=-f^{\prime \prime} k^{2}\left[s_{w} f\left(k^{d}\right) / k^{d}+\left(s_{K}-s_{w}\right) f^{\prime}\left(k^{d}\right)-n\right]+\xi_{2}\left(k / k^{d}-1\right) \\
& \dot{w}=-f^{\prime \prime} k\left(s_{K} f(k)+\left(s_{w}-s_{K}\right) w-n k\right)+\xi_{1}\left(k / k^{d}-1\right) .
\end{aligned}
$$


It is easy to see that the phase diagram now looks like figures 3 and 4.

Unlike an economy with (2.11) illustrated in Figures 1 and 2 , an economy with (2.12) shown in Figures 3 and 4 never switch regimes. This implies that the model does not predict a business cycle. Noting that a trajectory never crosses the full-employment regime, the following theorem is obvious from examining Figures 3 and 4 .

Theorem 4.1: A disequilibrium path described by $(U),(F)$, and (0) with (4.1), (4.2), and (4.3) replacing the wage adjustment equations, is globally stable if and only if the neoclassical path is stable, i.e., (2.19) is satisfied.

Figures 3 and 4 about here

5. Disequilibrium Dynamics and Comparative Statics

In this section, the implications of the results in the previous sections are examined.

\subsection{Short-run and Long-run Stability}

A disequilibrium growth path in a stable case can be viewed as "a sequence of short-run quantity-constrained equilibria toward the long-run market-clearing equilibrium." In a general (dis)equilibrium framework, a quantity-constraint in a market (the labor market in the present model) forces constrained agents to spill-over unsatisfied demand or supply into other markets (the goods market in the present 

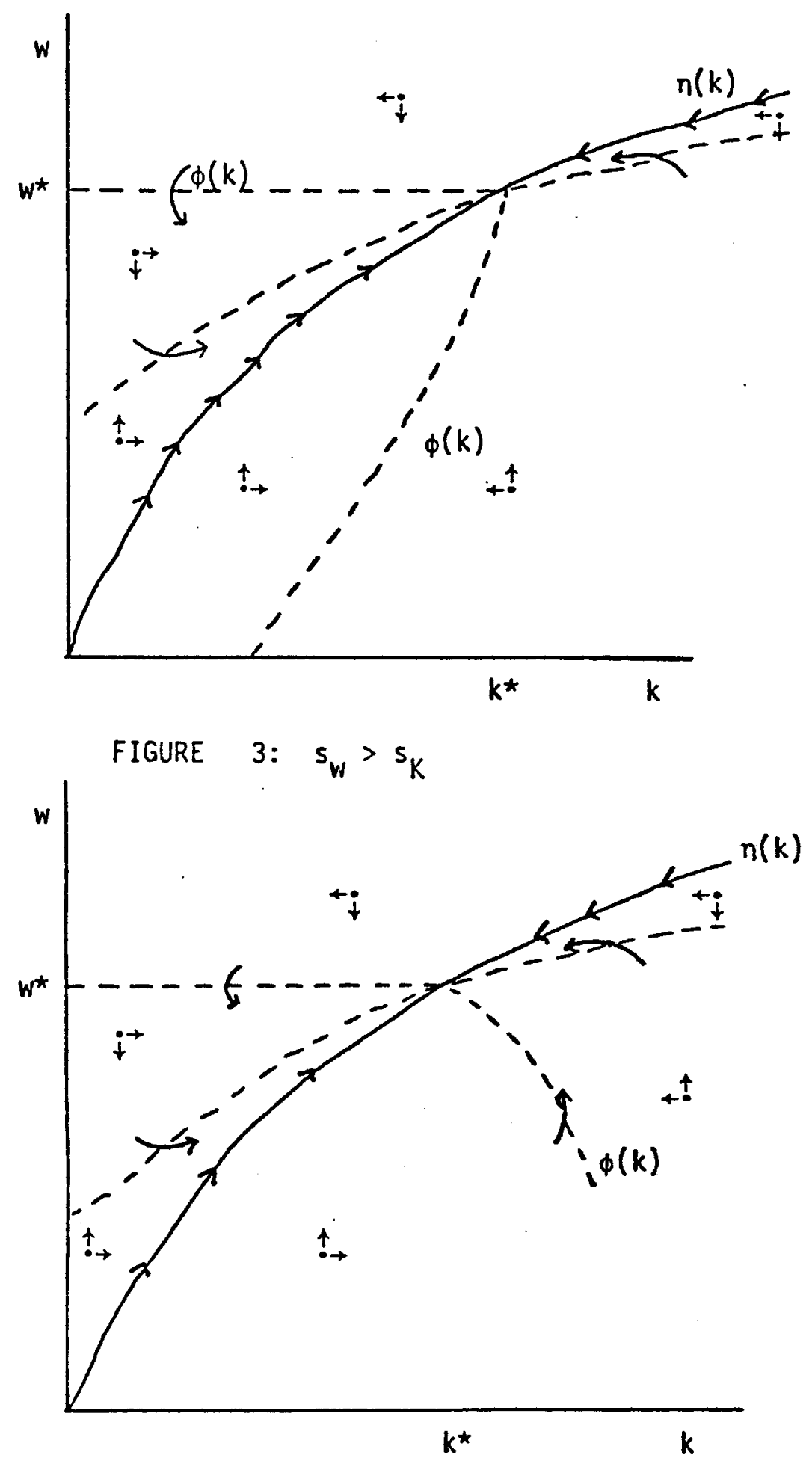

FIGURE $4: \quad s_{w}<s_{K}$ 
model) to form the "effective" demand (a Keynesian consumption function in the present model). If the number of markets in an economy is more than two, the existence of a quantity-constrained (fixed-price) equilibrium is not a trivial question, but a proposition to be proved. ${ }^{8}$ However, the present model is so simple that a spill-over from the labor market is always completely absorbed in the goods market. Therefore there is always a unique quantity-constrained equilibrium for the arbitrary wage rate and the arbitrary capital per capita. The stability of a sequence consisting of (short-run) quantity-constrained equilibria is a long-run phenomenon in the sense that the model incorporates capital accumulation.

\subsection{Business Cycles}

In the case that $s_{W}<s_{K}$ with the simple wage adjustment of (2.11), a disequilibrium path may oscillate around the equilibrium before the path converges, if ever, to the equilibrium. This is observed as business cycles characterized by unemployment periods (i.e., depressions) and overemployment periods (i.e., booms). In each type of period, there are two sub-periods; one is the "capital-deepening" period and the other is the "capital-shallowing" (or slower-capital-deepening in the case of Harrod neutral technological progress) period. Stability theorems in the preceding section suggest that a small displacement of the real wage rate or the capital per capita from the long-run steady state results in short-run disequilibrium in the labor market; but eventually the long-run equilibrium will be returned. 


\subsection{Long-run Fixed Price Equilibria}

We explained that any point in Figures $V . l$ and $V .2$ is viewed as a quantity constrained equilibrium given the fixed real wage in the short run. It is of interest to study a case where the real wage is fixed in the long run as well as in the short run. One may want to assume that the government or a powerfut trade union impose a fixed real wage for a certain period. Suppose that the real wage is fixed at less than the long-run steady state value, i.e., $\bar{w}<\hat{w}$, where $\bar{w}$ is the fixed real wage. Holding $w_{t}=\bar{w}$, for $t>0$, the economy will converge to some $k$ which induces no change in the capital per capita, i.e., $\dot{k}=0$. Such $k$ is calculated as $\bar{k}=\phi^{-1}(\bar{w})$. One finds the long-run fixed wage equilibrium, $(\bar{k}, \bar{w})$, in the overemployment regime. In the case of $s_{K}<s_{W}$, it is learned from Figure $V .1$ that $\bar{k}<\hat{k}$, i.e., the capital accumulation is short of the neoclassical long-run capital per capita. In the case of $s_{W}<s_{K}$, Figure V.2 tells us that $\hat{k}<\bar{k}$, i.e., the capital is over-accumulated relative to the neoclassical long-run capital per capita. By a similar exercise, we find that if $\bar{w}>\hat{w}$, then the capital is shallowing forever in both Figures $V .1$ and V.2. The most interesting case occurs when the real wage rate is set at the long-run equilibrium rate "prematurely" in the sense that the capital per capita is still below its long-run steady state value, i.e., $\bar{w}=\hat{w}, k_{t}<\hat{k}$. Then the economy is stuck at the current capital per capita, i.e., $\dot{k}_{t}=0$ for all $k_{t}<\hat{k}$ if $\bar{w}=\hat{w}$. Since it is under the unemployment regime, we observe that the steady state price signal, $\hat{w}$, may cause quantity-constrained (underemployed) 
equilibria, $(\hat{w}, \hat{k}), \hat{k}<\hat{k}$, as well as the full employment equilibrium. Let us state this proposition formally.

Theorem 5.1: There are unemployment equilibria, if the real wage rate is fixed at the steady state rate in the long run and if the capital per capita is below its steady state level.

\subsection{Comparative Statics}

Let us examine shifts of the steady states responding to changes in parameters. First, suppose that the saving rates from wage income and/or from profit increased. The full employment wage rate curve, $n\left(k_{t}\right)$, does not change, although the steady state $(\hat{k}, \hat{w})$ shifts to the north-east on the $n\left(k_{t}\right)$ curve. Therefore an economy will be in the overemployment capital-deepening regime in the transition period from the old to new steady states. A decrease in either one or both of the saving rates causes a symmetric change in the position of the steady state. However, the transition period should be in the unemployment capital shallowing regime. Cyclic behaviors may occur after any changes in the savings rate, if $s_{W}<s_{K}$ and the adjustment speeds of the wage rate are sufficiently small.

Secondly, suppose that there is a once-and-for-all shift in the production function. Assume that manna is in the form of an improved technology given in a multiplicatively separable form, i.e., $f(k)$ becomes $A f(k), A>1$. Then the full employment wage rate curve shifts upward, while the steady state shifts to the north-east. The transition period should be in the overemployment regime. 


\subsection{Technological Unemployment}

It is sometimes alleged among workers that technological progress causes unemployment, since a new machine usually replaces workers. For example, in 1811-12, the shearmen in Yorkshire, England, wrecked the newly invented machines that were about to displace them. This incidence is known as one of the Luddite Riots. ${ }^{9}$ Is it possible that technological progress decreases the aggregate demand for labor, so that the real wage is depressed? In other words, could technological progress cause unemployment if the real wage is sluggish downward? If so, it is quite contradictory to what is taught in neoclassical growth theory. According to neoclassical growth theory, technological progress is considered to be an important factor of economic growth and a source of real wage increase instead of decrease. Suppose that technological progress is of the Harrod-neutral type, which is compatible with the

"stylized facts" in the long run. 10 At the steady state, the real wage is increasing at the rate of technological progress. If new technology is interpreted as the upward shift of the rate of technological progress, then the rate of wage increase associated with the new steady state should be higher than one in the old steady state.

However, if one focuses attention on the family of steady states, one throws out the baby with the bathwater. The proper question to be asked concerning technological unemployment is how an economy moves from the old to new steady state. A study of the dynamic path of transition will give an insight to the problem of technological unemployment. A production function with Harrod-neutral technological progress is written as: 


$$
\begin{gathered}
-25- \\
Y=(K, A L),
\end{gathered}
$$

where $A$ is the technological level, which increases at a constant rate $\alpha$, i.e., $\alpha=\dot{M} / A$. Then existence and stability of a steady state can be analyzed in a parallel way just replacing $L$ (the natural unit of the labor force) by $M \equiv A L$ (the efficiency unit of the labor force). The capital-1abor (in the efficiency unit) ratio $k=K / M$, at a steady state is calculated as follows:

$$
\hat{k}=\left\{k \mid s_{w} f(k)-\left(s_{w}-s_{K}\right) k f^{\prime}(k)-(n+\infty) k=0\right\}
$$

At the steady state, the output per capita (in the natural unit), the capital per capita (in the natural unit), and the wage is increasing at the rate of technological progress. Suppose that an economy has been at a steady state and new invention suddenly spurts technological progress. The new rate of technological progress is $\alpha_{2}$. The steady state capital labor ratio, $\hat{k}_{2}$, is smaller than the old one. That is, at the old steady state the capital is overaccumulated compared to the new steady state. Therefore the transition from the old to new steady states involves a steady decrease in the capital-labor ratio. It remains to be investigated whether it is possible to observe that the absolute level of the wage of the natural unit declines temporarily, or at least the rate of wage increase is depressed temporarily to maintain full employment.

At any point in time the change in the wage in the natural unit, $w^{N}$, can be decomposed into that of efficiency units, $w^{E}$, and the change in technological progress: 


$$
\dot{w}^{N} / w^{N}=\dot{w}^{E} / w^{E}+\alpha .
$$

In order to maintain full employment, the wage of the efficiency unit should be changing according to equation (4.1). By (5.2), $\dot{w}^{N} / w^{N}=\alpha$ at the old steady state, $\hat{k}$. Suppose that the rate of technological progress changes to $\alpha_{2}$ from $\alpha$, where $\alpha_{2}>\alpha$. Then,

$$
\begin{aligned}
\dot{w}^{N} /\left.w^{N}\right|_{\hat{k}} & =\dot{w}^{E} /\left.w^{E}\right|_{\hat{k}}+\alpha_{2} \\
& =\frac{-f^{\prime \prime}(\hat{k}) \hat{k} \dot{k}}{f(\hat{k})-\hat{k} f^{\prime}(\hat{k})}+\alpha_{2},
\end{aligned}
$$

where $\dot{k}$ at $\hat{k}$ is written as follows using (5.1):

$$
\begin{aligned}
\dot{k} & =s_{w} f(\hat{k})-\left(s_{w}-s_{K}\right) \hat{k} f^{\prime}(\hat{k})-\left(n+\alpha_{2}\right) \hat{k} \\
& =-\left(\alpha_{2}-\alpha\right) \hat{k} .
\end{aligned}
$$

Substituting (5.4) into (5.3)

$$
\dot{w}^{N} / w^{N}=f^{\prime \prime}(\hat{k})(\hat{k})^{2}\left(\alpha_{2}-\alpha\right) /\left\{f(\hat{k})-\hat{k} f^{\prime}(\hat{k})\right\}+\alpha_{2} .
$$

If (5.5) is negative, then the wage should decrease because of a spurt of technological progress. If $(5.5)$ is positive but smaller than $\alpha$, then the wage increase slows down because of the spurt from $\alpha$ to $\alpha_{2}$. In order to derive economic implications out of (5.5), we rewrite it using the elasticity of substitution, $\sigma$, in the form of (2.18):

$$
\dot{w}^{N} / w^{N}=-\left(\alpha_{2}-\alpha\right) \hat{k} f^{\prime}(\hat{k}) / \sigma f(\hat{k})+\alpha_{2} .
$$

Therefore, the following theorem is true. 
Theorem 5.1 When there is a spurt of technological progress,

(i) the real wage in the natural unit decreases to maintain full employment if and only if,

$$
\sigma<\left(1-\frac{\alpha}{\alpha_{2}}\right) \frac{\hat{k} f^{\prime}(\hat{k})}{f(\hat{k})},
$$

the increase of the real wage slows down to maintain full employment if and only if,

$$
\sigma<\frac{\hat{k} f^{\prime}(\hat{k})}{f(\hat{k})}
$$

The right-hand sides of (5.7) and (5.8) are less than unity because of the concavity of the production function and the assumption of $\alpha_{2}>\alpha$. Therefore if the production function is the Cobb-Douglas type, i.e., $\sigma=1$, then a technological spurt will immediately increase the rate of wage increase. The above theorem also implies that for a sufficientiy small value for the elasticity of substitution, it is possible that technological spurt causes temporary technological unemployment if the wage is sluggish. This is intuitively straightforward, since a low elasticity of substitution implies that the labor force as a result of the technological spurt cannot substitute for capital without drastically altering the rental-wage ratio. 


\section{Concluding Remarks}

I have demonstrated the idea of disequilibrium growth theory in a simple one-sector model. It has several attractive features: explicit analysis of spill-over effects in a general (dis) equilibrium framework; and simultaneous adjustment of prices and quantities in the long run as a sequence of short-run fixed price equilibria. However, the power of analysis is severely limited by the fact that there is only one malleable commodity. The model is philosophically classical (or anti-Keynesian) in the sense that the supply side determines output. The disequilibrium labor market determines the actual employment at the minimum of demand and supply. This in turn determines actual output, which is exactly absorbed either as consumption or capital accumulation. This story is clearly what Keynes and his "faithful" followers attack. This may seem paradoxical because disequilibrium macroeconomic models are praised mainly because they claim to be the restoration of "Keynes's economics" as opposed to "Keynesian economics."

The present disequilibrium growth model is a hybrid of a neoclassical growth theory and a disequilibrium macroeconomic model, and the anti-Keynesian nature is inherited from neoclassical growth theory, i.e., a one-sector model without money. It remains for a further research to integrate disequilibrium macroeconomics with stochastic rationing in the preceding chapter and monetary growth theory. 
NOTES

I Growth theory is a much explored field which studies an economy with accumulating capital, increasing population, technological progress, and changes in factor shares. For best surveys, Hahn and Matthews (1964) and Burmeister and Dobell (1970) should be consulted. We have two different breeds of growth theory: First, Keynesian growth theory, started by Harrod (1943) and Domar (1957), emphasizes the instability of the warranted growth rate. Secondly, neoclassical growth theory, initiated by Solow (1956) and Swan (1956), shows the stability of the steady state. Keynesian instability essentially comes from non-substitutability, i.e., fixed coefficients, of factors for production. The Keynesian growing economy will find itself in either chronic inflation or persistent unemployment, while factors are always fully employed by the assumption of perfect price flexibility and smooth factor substitutions in the neoclassical growing economy. Since substitutions between labor and capital seem plausible in the long run, the neoclassical models outnumbered the Keynesian models during the most fruitfut period of research. But neoclassical models could not account for unemployment.

${ }^{2}$ There have been several works on "disequilibrium growth" or "unemployment in a theory of growth." Tobin (1955) showed that when the nominal wage is inflexible downward, an economy may experience cyclic fluctuations or stagnation depending upon whether the short-run 
adjustment is unstable or stable, respectively. Although the ideas are similar, our model benefits from several features derived from the modern disequilibrium macro-models, such as ability to trace disequilibrium dynamic paths of the capital per capita. Rose $(1966,1967)$ constructed a model to incorporate unemployment. However, he merely replaces some equalities of the equilibrium conditions by lagged adjustment equations. Hadjimichalakis' model (1971) also adopts lagged adjustment equations instead of instantaneous equalities of Tobin's monetary growth model. Hahn (1960) studied seemingly disequilibrium models where lagged adjustments are introduced both in prices and the capital-labor ratio. In his model $A$, the real rental rate is not always equal to the marginal productivity of capital while the instantaneous adjustment of the nominal wage makes the real wage equal to the marginal productivity of labor. Model $B$ is a case where both marginal productivities may deviate from the real input price. However, if both real input prices are higher than their corresponding productivities, then firms are making negative profits. My approach is different from the above works by two features: the minimum transaction rule in the disequilibrium market is introduced and unsatisfied demand or supply spills over to the other markets. These features are inherited from disequilibrium macroeconomic models.

${ }^{3}$ This is similar to Kaldor's (1960) hypothesis. However, the original Kaldor hypothesis was that the profit saving rate is not only different but higher than the wage saving rate, although the Diamond 
model, or the life-cycle hypothesis in general, implies the opposite. Modigliani (1975) discussed theoretical and empirical comparisons between the Kaldor hypothesis and the life-cycle hypothesis. Since I take the Kaldor model where the saving rate of workers is higher than that of capitalists as an approximation of an overlapping generations model, the Pasinetti paradox in Samuelson and Modigliani (1966) does not appear as a problem.

${ }^{4}$ The qualitative nature of the model would not change even if the labor supply per capita depends on the wage rate. Assume that $\ell(0)=0$, $\lim \ell(w)<\infty$, and $\ell^{\prime}(w)>0$ for $0 \leq w<\infty$. Then aimost all the $w \rightarrow \infty$

analysis except in the case of overemployment with $s_{K}>s_{W}$ goes through, by replacing $k$ by $k / \ell(w)$ in the following.

${ }^{5}$ For the derivation of (2.18), see Allen (1967; Section 3.6).

${ }^{6}$ Suppose that we have two systems of differential equations. Assume both have stable elliptic solution paths around the equilibrium. However, one has a major axis horizontally, while the other vertically. Patch these systems in such a way that the solution path always goes from a point on a minor axis to that of a major axis, then the patchedup system is globally unstable.

7 Veendorp (1975) faced a similar problem of stability with switching regimes. The sufficient condition he used cannot be applied in our problem, since the $\dot{k}=0$ line in the unemployment regime is 
horizontal. Our condition for local stability cannot be applied to Veendorp's problem, either, because he has four regimes instead of two.

${ }^{8}$ See Benassy (1975) and Drèze (1975).

${ }^{9}$ See Hammond and Hammond (1926) for a detailed description of the cause of the riots.

${ }^{10}$ The stylized facts are summarized in Solow (1970; pp. 2-3): (1) Real output per man-hour grows at a more or less constant rate over fairly long periods of time; (2) the stock of capital grows at a more or less constant rate exceeding the rate of growth of labor input; (3) the rates of growth of real output and the stock of capital goods tend to be about the same; and (4) the rate of profit on capital has a horizontal trend. 


\section{REFERENCES}

Allen, R. G. D. (1967), Macroeconomic Theory, London: Macmillan.

Barro, R. J. and H.I. Grossman (1971), "A General Disequilibrium Model of Income and Employment," American Economic Review, Vol. 61, March: 82-93.

(1976), Money, Employment and Inflation, Cambridge: Cambridge University Press.

Benassy, J.-P. (1975), "Neo-Keynesian Disequilibrium in a Monetary Economy," Review of Economic Studies, Vo1. XLII, October: 503-524.

Böhm, V. (1978), "Disequilibrium Dynamics in a Simple Macroeconomic Model," Journal of Economic Theory, Vol. 17, April: 179-199.

Burmeister, E. and A. R. Dobell (1970), Mathematical Theories of Economic Growth, London: Macmillan.

Clower, R. W. (1965), "The Keynesian Counter-Revolution: A Theoretical Appraisal," in F. H. Hahn and F.P.R. Brechling (eds.), The Theory of Interest Rates, London: Macmillan.

Diamond, P. (1965), "National Debt in a Neoclassical Growth Model," American Economic Review, Vol. LV, December: 1126-1135.

Domar, E. D. (1957), Essays in the Theory of Growth, London: Oxford University Press.

Drèze, J. H. (1975), "Existence of an Exchange Equilibrium under Price Rigidities," International Economic Review, Vol. 16: 301-320. Hadjimichalakis, M. G. (1971), "Equilibrium and Disequilibrium Growth with Money - The Tobin Models," Review of Economic Studies, Vo1. XXXVII, No. 4, October: 457-480. 
Hahn, F. H. (1960), "The Stability of Growth Equilibrium," Quarterly Journal of Economics, Vol. 74, May: 206-226.

Hahn, F. H. and R. C. 0. Matthews (1964), "The Theory of Economic Growth:

A Survey," Economic Journal, Vol. 74, December: 779-902.

Hammond, J. L. and B. Hammond (1926), The Rise of Modern Industry, New York: Harcourt, Brace.

Harrod, R. F. (1943), Towards a Dynamic Economics, London: Macmillan. Henry, C. (1972), "Differential Equations with Discontinuous Right-Hand Side for Planning Procedures," Journal of Economic Theory, Vol. 4, 547-557.

Hildenbrand, K. and W. Hildenbrand (1978), "On Keynesian Equilibria with Unemployment and Quantity Rationing," Journal of Economic Theory, Vor. 18, 255-277.

Honkapohja, S. (1978), "On the Dynamics of Disequilibria in a Macro Model with Flexible Wages and Prices," in M. Aoki and A. Marzollo (eds.) New Trends in Dynamic System Theory and Economics, New York: Academic . Press.

Honkapohja, S. (1979), "The Employment Multiplier after Disequilibrium Dynamics," H.I.E.R. discussion paper, No.686, Harvard University, February.

Ito, T. (1978), "A Note on Disequilibrium Growth Theory," Economics Letters, Vol. 1, 45-49.

Kaldor, N. (1960), Essays in Value and Distribution, London: Duckworth. 
Leijonhufvud, A. (1968), On Keynesian Economics and the Economics of Keynes, London: Oxford University Press.

Mal invaud, E. (1977), The Theory of Unemployment Reconsidered, Oxford: Basil B1ackwell.

Modigliani, F. (1975), "The Life Cycle Hypothesis of Saving Twenty Years Later," in M. Parkin, Contemporary Issues in Economics, Manchester University Press: 1-36.

Muellbauer J. and R. Portes (1978), "Macroeconomic Models with Quantity Rationing," Economic Journal, Vol. 86, December.

Rose, H. (1966), "Unemployment in a Theory of Growth," International Economic Review, Vol. 7, September: 260-282.

, (1967), "On the Non-Linear Theory of the Employment Cycle," Review of Economic Studies, Vol. XXXIV, April: 153-174.

Samuelson, P. A. and F. Modigliani (1966), "The Pasinetti Paradox in Neoclassical and More General Models," Review of Economic Studies, Vo1. XXXIII, October: 269-298.

Solow, R. M. (1956), "A Contribution to the Theory of Economic Growth," Quarterly Journal of Economics, Vol. LXX, February: 65-94.

$\longrightarrow$ (1970), Growth Theory, 0xford: Clarendon, 1970.

Swan, T. W. (1956), "Economic Growth and Capital Accumulation," Economic Record, Vol. XXXII, November: 334-361.

Tobin, J. (1955), "A Dynamic Aggregative Model," Journal of Political Economy Vo1. 63, Apri1: 115-132.

Veendorp, E. C. H. (1975), "Stable Spillovers Among Substitutes," Review of Economic Studies, Vol. 42, 445-456. 


\section{APPENDICES}

\section{APPENDIX 1}

A proof of Theorem 2.1 is routine in a neoclassical growth model. Note that

$$
\dot{k}=0 \text { iff } \quad \dot{K} / K-\dot{N} / N=0 \text {. }
$$

Since $\dot{N} / N=n$, a constant with a finite value, the following condition is enough to assert the existence, uniqueness, and globally asymptotic stabitity of the steady state:

(i) $\quad \lim _{k \rightarrow 0}(\dot{k} / k)=\infty$

(ii) $\lim _{k \rightarrow \infty}(\dot{k} / K)<n$

(iii) $\frac{d}{d k}\left(\frac{\dot{K}}{K}\right)$ exists and is strictly negative for $k>0$.

Now recal1 that $\dot{K} / K=s_{w} f(k) / k+\left(s_{K}-s_{w}\right) f^{\prime}(k)$

$$
\begin{aligned}
\lim _{k \rightarrow \infty}(\dot{K} / K) & =s_{w} \lim _{k \rightarrow \infty} \frac{f(k)}{k} \\
& =s_{w}\left[\lim _{k \rightarrow \infty} f^{\prime}(k)\right] /\left[\lim _{k \rightarrow \infty} 1\right] \\
& =0, \quad \text { (ii) is proved. }
\end{aligned}
$$

To prove (i), we rewrite $\dot{K} / K$ as follows: 


$$
\begin{gathered}
\dot{k} / K=s_{W}\left\{f(k)-k f^{\prime}(k)\right\} / k+s_{K} f^{\prime}(k) \\
\lim _{k \rightarrow 0}(\dot{K} / K)=s_{w} \frac{\lim _{k \rightarrow 0}-f^{\prime \prime}(k) k}{\lim _{k \rightarrow 0} 1}+\infty=\infty, \text { (i) is proved. }
\end{gathered}
$$

It is obvious that $\dot{K} / K$ is differentiable by an assumption on $F$.

$$
\begin{aligned}
& \frac{d}{d k}\left(\frac{\dot{K}}{k}\right)=s_{w^{\prime}}\left[-k^{2} f^{\prime \prime}(k)-\left\{f(k)-k f^{\prime}(k)\right\}\right] / k^{2}+s_{K} f^{\prime \prime}(k) . \\
& \frac{d}{d k}\left(\frac{K}{k}\right)<0 \quad \text { iff } \quad \frac{-\left\{f(k)-k f^{\prime}(k)\right\}}{k^{2} f^{\prime \prime}(k)}-1>-\frac{s_{K}}{s_{w}} \\
& \text { or } \quad-\frac{f^{\prime}(k)\left\{f(k)-k f^{\prime}(k)\right\}}{k f(k) f^{\prime \prime}(k)}>\left(1-\frac{s_{K}}{s_{w}}\right) \frac{k f^{\prime}(k)}{f(k)} .
\end{aligned}
$$

Now the LHS of the last inequality is the definition of the elasticity, (2.18). Therefore, if $\sigma>\left(1-\frac{s_{K}}{s_{W}}\right) \frac{k f^{\prime}(k)}{f(k)}$, which is exactly the stability condition, (2.19), then (iii) is true. Q.E.D. 
We derive the relations (2.25) and (2.26)

$$
\begin{aligned}
\phi(k)-n(k) & =\left\{n k-s_{K} f(k)\right\} /\left(s_{W}-s_{K}\right)-\left[f(k)-k f^{\prime}(k)\right] \\
& =\left[n k-s_{W} f(k)+\left(s_{W}-s_{K}\right) f^{\prime}(k) k\right] /\left(s_{W}-s_{K}\right) \\
& =\left[s_{W} f(k)-\left(s_{W}-s_{K}\right) f^{\prime}(k) \cdot k-n k\right] f\left(s_{K}-s_{W}\right) .
\end{aligned}
$$

Note that $[\cdot]$ in the last line is the definition of $\dot{k}$ in the full employment regime, i.e., equation (2.15). Therefore

(i) $\phi(\hat{k})=n(\hat{k})$, and $\phi(k) \neq n(\hat{k})$ for $k \neq \hat{k}$,

(ii) if $s_{K}<s_{W}$ and $\hat{k} \leq k$, i.e., $\left.\dot{k}\right|_{\dot{k}=(2.15)} \leq 0$, then $\phi(k) \geq n(k)$, respectively.

(iii) if $s_{w}<s_{k}$ and $\hat{k} \leq k$, i.e., $\left.\dot{k}\right|_{\hat{k}=(2.15)} \leq 0$, then $\phi(k) \leq n(k)$, respectively.

Next, we check the sign of $\phi^{\prime}$ at $k=\hat{k}$.

$$
\begin{aligned}
\phi^{\prime}(k)=\left.\frac{d w}{d k}\right|_{\substack{k, w) \varepsilon R_{0} \\
k=0}} & =-\left.\frac{\partial \dot{k} / \partial k}{\partial \dot{k} / \partial w}\right|_{\substack{k=0 \\
k, w) \varepsilon R_{0}}} \\
& =-\left.\frac{s_{K} f^{\prime}(k t)-n}{s_{w}-s_{K}}\right|_{\substack{(k, w) \varepsilon R_{0} \\
k=0}}
\end{aligned}
$$


$-39-$

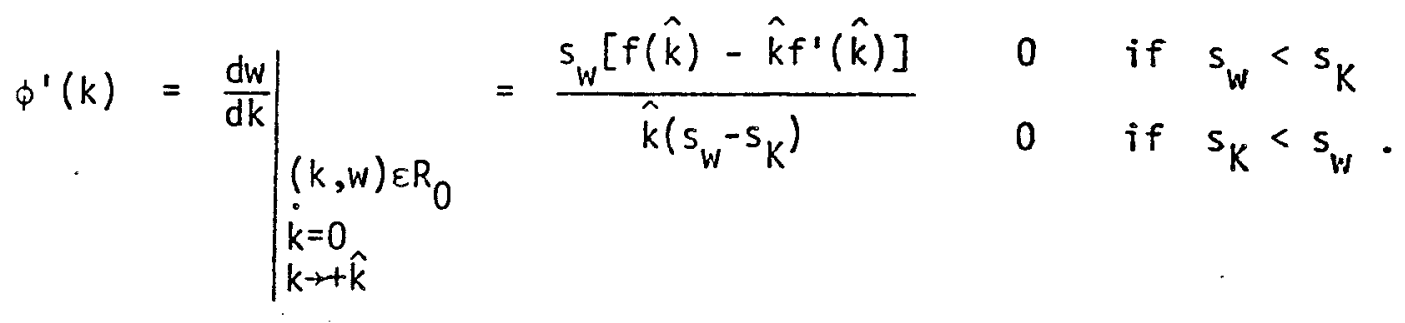


APPENDIX 3

First, we establish a theorem on the (global/local) stability of linear differential equations in a two dimensional Euclidean space.

Suppose that two sets of linear differential equations are defined on $\mathbf{R}^{2}$, assuming that the origin is the equilibrium point without loss of generality:

$$
\begin{array}{ll}
\left(\begin{array}{l}
\dot{x} \\
\dot{y}
\end{array}\right)=\left(\begin{array}{ll}
a_{1} & b_{1} \\
c_{1} & d_{1}
\end{array}\right)\left(\begin{array}{l}
x \\
y
\end{array}\right) \quad(x, y) \in \mathbf{R}^{2} \\
\left(\begin{array}{l}
\dot{x} \\
\dot{y}
\end{array}\right)=\left(\begin{array}{ll}
a_{2} & b_{2} \\
c_{2} & d_{2}
\end{array}\right)\left(\begin{array}{l}
x \\
y
\end{array}\right) & (x, y) \in \mathbf{R}^{2} .
\end{array}
$$

A "patched-up" system with a linear boundary is defined by the following:

$$
\begin{aligned}
& \left(\begin{array}{l}
\dot{x} \\
\dot{y}
\end{array}\right)=\left(\begin{array}{ll}
a_{i} & b_{i} \\
c_{i} & d_{j}
\end{array}\right)\left(\begin{array}{l}
x \\
y
\end{array}\right) \quad \begin{array}{l}
i=1 \text { if }(x, y) \in R_{I} \\
i=2 \text { if }(x, y) \in R_{I I}
\end{array} \\
& R_{I}=\left\{x \in R^{2} \mid h x+k y \geq 0\right\} \\
& R_{I I}=\left\{x \in R^{2} \mid h x+k y<0\right\} .
\end{aligned}
$$

There exists at least one solution path for $(*)$, if solution paths are connected properly over the boundary, $h x+k y=0$ : a solution path at a point on the boundary coming from one region has to go out to the other region. In other words, the direction of solution curves 
on the linearized boundary relative to the direction of the boundary itself should agree for both systems of differential equations. Existence of such a path is guaranteed by Henry (1972).

In mathematical notation

$$
\left(\begin{array}{ll}
h & k
\end{array}\right)\left(\begin{array}{ll}
a_{1} & b_{1} \\
c_{1} & d_{1}
\end{array}\right)\left(\begin{array}{c}
k \\
-h
\end{array}\right) \quad(h k)\left(\begin{array}{ll}
a_{2} & b_{2} \\
c_{2} & d_{2}
\end{array}\right)\left(\begin{array}{l}
k \\
-h
\end{array}\right)>0 .
$$

Assume that $(* 1)$ and $(* 2)$ have a unique (common) equilibrium on the boundary; $\exists \cdot(\hat{x}, \hat{y})$, such that $h \hat{x}+k \hat{y}=0$ and

$$
\left(\begin{array}{ll}
a_{i} & b_{i} \\
c_{i} & d_{i}
\end{array}\right)\left(\begin{array}{l}
\hat{x} \\
\hat{y}
\end{array}\right)=\left(\begin{array}{l}
0 \\
0
\end{array}\right) \quad i=1,2 .
$$

Theorem A: Suppose a piecewise linear differential equation system defined by $(*)$ satisfies condition (E). If the unique equilibrium is stable with $(* 1)$ and $(* 2)$

$$
a_{i}+d_{i}<0
$$

$$
a_{i} d_{i}-b_{i} c_{i}>0, \quad i=1,2 \text {. }
$$

then the "patched-up" system with a linear boundary, $(*)$, has a stable solution path, i.e.,

$$
\begin{aligned}
& \lim _{t \rightarrow \infty} x\left(t \mid\left(x_{0}, y_{0}\right)\right)=\hat{x} \\
& \lim _{t \rightarrow \infty} y\left(t \mid\left(x_{0}, y_{0}\right)\right)=\hat{y} \quad \text { for }\left(x_{0}, y_{0}\right) \varepsilon \mathbb{R}^{2} .
\end{aligned}
$$


Proof of Theorem A: First, note that the $i$-th systen of differential equations is symmetric about the origin:

$$
\left(\begin{array}{ll}
a_{i} & b_{i} \\
c_{i} & d_{i}
\end{array}\right)\left(\begin{array}{c}
-x \\
-y
\end{array}\right)=-\left(\begin{array}{ll}
a_{i} & b_{i} \\
c_{i} & d_{i}
\end{array}\right)\left(\begin{array}{l}
x \\
y
\end{array}\right), \quad \quad i=1,2 .
$$

Secondly, the system is homogeneous:

$$
\left(\begin{array}{ll}
a_{i} & b_{i} \\
c_{i} & d_{i}
\end{array}\right)\left(\begin{array}{ll}
m & x \\
m & y
\end{array}\right)=m\left(\begin{array}{ll}
a_{i} & b_{i} \\
c_{i} & d_{i}
\end{array}\right)\left(\begin{array}{l}
x \\
y
\end{array}\right), \quad m>0 ; i=1,2 .
$$

Now consider a solution path starting from $\left(x_{0}, y_{0}\right)$, a point on the boundary. Let us define a solution path of $(*)$ as

$$
\begin{aligned}
&\left\{\left(x_{t}, y_{t}\right) \mid\left(x_{0}, y_{0}\right)\right\} \text { where } x_{t}=x\left(t \mid\left(x_{0}, y_{0}\right)\right) \\
& y_{t}=y\left(t \mid\left(x_{0}, y_{0}\right)\right) \\
& \text { such that } \quad h x_{0}+k y_{0}=0 .
\end{aligned}
$$

Since a solution path of either (*1) or (*2) alone must converge to the origin, the solution path $\left\{\left(x_{t}, y_{t}\right) \mid\left(x_{0}, y_{0}\right)\right\}$ must either converge to the origin without switching regimes, or intersect the boundary to switch regimes. I claim that $\left\{\left(x_{t}, y_{t}\right) \mid\left(x_{0}, y_{0}\right)\right\}$ must intersect the interval, $\left(\left(-x_{0}, y_{0}\right),(0,0)\right)$ before the first switching, if any, of regimes.

Once the above claim is proved, every time regimes switch one from another, the distance of switching point from the origin shrinks. 
Moreover, by the homogeneity the ratio of shrinking (of every two switchings) stays constant, so that $\left\{\left(x_{t}, y_{t}\right) \mid\left(x_{0}, y_{0}\right)\right\}$ does converge to the origin.

The solution path $\left\{\left(x_{t}, y_{t}\right) \mid\left(x_{0}, y_{0}\right)\right\}$ is directed (i) toward the origin staying on the linearized boundary, (ii) away from the origin staying on the linearized boundary, or ( $i i i)$ toward the interior of one of the two regimes, say, $R_{I}$ without loss of generality. In a case of (ii), it violates the stability of each system itself, (S). In case of ( $i$ ), the solution path converges to the origin whenever it starts at the linearized boundary. It implies that a solution path starting at an arbitrary initial point stays in the same region forever (because solution paths cannot "meet" or "cross"). Therefore (S) is enough to assert that $(*)$ is locally asymptotically stable. In a case of (iii), we need a careful examination. By homogeneity, $(H)$, directions of solution paths starting at all points on a linearized boundary on the side of $\left(x_{0}, y_{0}\right)$ are proportional. Therefore a solution path starting from $\left(x_{0}, y_{0}\right)$ cannot intersect that side of the linearized boundary as the first switching point. Next suppose that the solution path overshoots the origin and intersects the linearized boundary further than the point antipodal to the initial point. If the I-st system of differential equations is defined for the entire plane, the solution path starting at $\left(-x_{0},-y_{0}\right)$ according to $(* 1)$ must have a symmetric path to the one starting from $\left(x_{0}, y_{0}\right)$ by $(Y)$, and must intersect the linearized boundary beyond $\left(x_{0}, y_{0}\right)$. This impties the I-st system of differential equations is unstable, and contradicts assumption ( $S$ ). 
The above examination leaves the possibility that the solution path must intersect somewhere in $\left[(0,0),\left(-x_{0},-y_{0}\right)\right)$ after travelling in $R_{I}$. In the case of arriving at the origin, other solution paths starting anywhere in $\left((0,0),\left(x_{0}, y_{0}\right)\right)$ should arrive at the origin by homogeneity. Now suppose that the solution path arrives at $\left(-x_{1},-y_{1}\right) \in\left(\left(-x_{0},-y_{0}\right),(0,0)\right)$, where the system switches to the II-nd set of differential equations. However, the parallel argument to the above applies to a solution path starting at $\left(-x_{1},-y_{1}\right)$, so that it must intersect the interval $\left[(0,0),\left(x_{1}, y_{1}\right)\right)$. Repeat this process and have the converging path to the origin obeying the "patched-up" system of differential equations. It is obvious, by homogeneity, that any solution path starting from a point in $\left((0,0),\left(x_{0}, y_{0}\right)\right)$ should proportionately shrink its distance from the origin everytime it crosses the boundary of the $\left(x_{0}, y_{0}\right)$ side. Finally, we note that any path starting at an interior point of a region should converge to the origin travelling only within the region or intersect the boundary to go into the other region, since otherwise it contradicts (S). For the latter case, examine the behavior after the intersecting point at boundary and it has been proved to converge to the origin. Q.E.D.

Next, I show the local stability of a "patched-up" system of nonlinear differential equations.

Suppose that $\mathbb{R}^{2}$ is partitioned into two regions, $R_{I}$ and $R_{I I}$ in such a way that $R_{I} \cup R_{I I}=R^{2}$ and $S=R_{I} \cup R_{I I}$ is a connected line. In each phase a system of differential equations which satisfy the Lipschitz condition is defined: 
$\left(N^{*}\right)$

$$
\begin{aligned}
(\dot{x}, \dot{y})=\left(f_{j}(x, y), g_{j}(x, y)\right), i & =I \text { if }(x, y) \varepsilon \tilde{R}_{I} \\
i & =I I \text { if }(x, y) \varepsilon \tilde{R}_{I I},
\end{aligned}
$$

where $\tilde{R}_{I}$ and $\tilde{R}_{I I}$ are open neighborhoods of $R_{I}$ and $R_{I I}$, respectively, and $f_{j}$ and $g_{j}$ are of $C^{l}$ class.

Note that at any point on the boundary which separates two regions, a solution path travelling over the two regions is connected smoothly, i.e., $f_{i}$ and $g_{i}$ are continuous over the two regions:

$$
\left(f_{I}(x, y), g_{I}(x, y)\right)=\left(f_{I I}(x, y), g_{I I}(x, y)\right) \quad \forall(x, y) \varepsilon S .
$$

Suppose also that both systems of differential equations have a unique common equilibrium point;

$$
(\hat{x}, \hat{y}) \varepsilon S, \quad\left(f_{i}(\hat{x}, \hat{y}), g_{i}(\hat{x}, \hat{y})\right)=(0,0) \quad i=I, I I .
$$

Let us define $S$ by

$$
S=\{(x, y) \mid n(x, y)=0 \text { where } n(\hat{x}, \hat{y})=0\} \text {. }
$$

Suppose $\eta$ is differentiable at $(\hat{x}, \hat{y})$. Then the linearized boundary is defined by

$$
s^{l}=\left\{(x, y) \mid \hat{n}_{x} x+\hat{n}_{y} y=0\right\} \quad,
$$

where $\hat{n}_{x}$ and $\hat{n}_{y}$ denote partial derivatives of $n$ with respect to $x$ and $y$, respectively, evaluated at $(\hat{x}, \hat{y})$.

Next we assume that even if the boundary is linearized, condition $(E)$ is met for the linearized differential equations on the linearized boundary. 


$$
\left[\left(\hat{n}_{x}, \hat{n}_{y}\right) \hat{J}_{1}\left(\hat{n}_{-\hat{n}_{x}}\right)\right]\left[\left(\hat{n}_{x}, \hat{n}_{y}\right) \hat{\jmath}_{I I}\left(\begin{array}{c}
\hat{n}_{y} \\
-\hat{n}_{x}
\end{array}\right)\right]>0
$$

Here $\hat{J}_{j}$ denotes the Jacobian matrix of the $i$-th system of differential equations evaluated at $(\hat{x}, \hat{y})$. This condition is required because a solution path may not be smooth at a point on the linearized boundary any more. In other words, $f_{I} \neq f_{I I}$ and $g_{I} \neq g_{I I}$ on $s$. However, we need the condition for the same reason we had (E) for Theorem $A$.

Theorem B: If each system of non-linear differential equations is locally asymptotically stable around the equil ibrium point, i.e.,

$$
\operatorname{tr} \hat{j}_{i}<0 \quad i=I, I I
$$

$$
\operatorname{det} \hat{\jmath}_{i}>0 \quad i=I \text {, II, }
$$

then the "patched-up" system of differential equations, $\left(N^{*}\right)$ is locally asymptotically stable: there exists $\delta>0$ such that $\left\{(x, y) \mid t ;\left(x_{0}, y_{0}\right)\right\}$ $\rightarrow(\hat{x}, \hat{y})$, as $t \rightarrow \infty$, if $\left\|\left(x_{0}, y_{0}\right)-(\hat{x}, \hat{y})\right\|<\delta$.

A proof of Theorem B is trivial, since the linearized differential equations around the equilibrium point satisfies the conditions for Theorem A:

$$
\left(\begin{array}{c}
\dot{x} \\
\dot{y}
\end{array}\right)=\hat{j}_{i}\left(\begin{array}{l}
x \\
y
\end{array}\right) \quad \begin{aligned}
& i=I \text { if }(x, y) \varepsilon R_{I}^{l} \\
& i=I I \text { if }(x, y) \in R_{I I}^{l},
\end{aligned}
$$

where $R_{I}^{l}$ and $R_{I I}^{l}$ denote the two regions which are separated by the common boundary, $s^{\ell}$.

Now we are ready to prove Theorem 3.2 . 
Proof of Theorem 3.2: Confirm that. (U) and (0) satisfy the conditions of $(*)$, and others in Theorem $A: S$ in Theorem $B$ is defined by $R_{f}$, in Theorem 3.2; and set $R_{I}=R_{U}$ and $R_{I I}=R_{0}$. Then a patched-up system of (U) and (0) has the local stability at $(\hat{k}, \hat{w})$ by applying Theorem A, if each system has local stability independently.

For the unemployment regime:

$$
\begin{aligned}
& \left.\frac{\partial \dot{k}}{\partial k}\right|_{\substack{k=\hat{k} \\
w=\hat{w}}}=0 \\
& \left.\frac{\partial \dot{k}}{\partial w}\right|_{\substack{k=\hat{k} \\
w=\hat{w}}}=\frac{-1}{f^{\prime \prime}(\hat{k})}\left[\frac{s_{w}}{(\hat{k})^{2}}\left\{f^{\prime}(\hat{k}) \cdot \hat{k}-f(\hat{k})-(\hat{k})^{2} f^{\prime \prime}(\hat{k})\right\}+s_{K} f^{\prime \prime}(\hat{k})\right]<0
\end{aligned}
$$

by the condition, (2.19) and the logic in Appendix 1.

$$
\begin{aligned}
& \left.\frac{\partial \dot{w}}{\partial k}\right|_{\substack{k=\hat{k} \\
w=\hat{w}}}=\xi_{2} / \hat{k}>0 \\
& \left.\frac{\partial \dot{w}}{\partial w}\right|_{\substack{k=\hat{k} \\
w=\hat{w}}}=\frac{\xi_{2}}{f^{\prime \prime}(\hat{k})(\hat{k})^{2}}<0 .
\end{aligned}
$$

Therefore,

$$
\begin{array}{ll}
\operatorname{sign} J_{u}(\hat{k}, \hat{w})=i_{-}^{0}- \\
\operatorname{tr} J_{u}(\hat{k}, \hat{w})<0 \\
\text { det } J_{u}(\hat{k}, \hat{w})>0 .
\end{array}
$$


In the overemployment phase: $\frac{\partial \dot{k}}{\partial \dot{k}}=s_{K^{\prime}} f^{\prime}(k)-n$, and

$$
\begin{aligned}
\left.\frac{\partial \dot{k}}{\partial \dot{k}}\right|_{\substack{k=\hat{k} \\
w=\hat{w}}} & =s_{K^{\prime}} f^{\prime}(\hat{k})-\frac{s_{w} f(\hat{k})}{\hat{k}}+\left(s_{w^{-}} s_{K}\right) f^{\prime}(\hat{k}) \\
& =s_{w}\left(f^{\prime}(\hat{k})-\frac{f(\hat{k})}{\hat{k}}\right)<0
\end{aligned}
$$

$$
\begin{aligned}
& \left.\frac{\partial \dot{k}}{\partial w}\right|_{\substack{k=\hat{k} \\
w=\hat{w}}}=s_{w}-s_{K}<0 \quad \text { if } s_{w}<s_{K} \\
& \left.\frac{\partial \dot{w}}{\partial k}\right|_{\substack{k=\hat{k} \\
w=\hat{w}}}=\xi_{7} / \hat{k}>0 \\
& \left.\frac{\partial \dot{w}}{\partial w}\right|_{\substack{k=\hat{k} \\
w=\hat{w}}}=\xi_{\eta} /(\hat{k})^{2} f^{\prime \prime}(\hat{k})<0 .
\end{aligned}
$$

Therefore sign $J_{0}(k, w)=\left(_{+}^{-}\right)_{-}^{-}$

$$
\begin{aligned}
& \operatorname{tr} J_{0}(\hat{k}, \hat{w})<0 \\
& \operatorname{det} J_{0}(\hat{k}, \hat{w})>0 .
\end{aligned}
$$

Lastiy we confirm that condition (E), the existence of a solution path on the linearized boundary, is satisfied. In our economy $\eta_{x}=$ $f^{\prime \prime}(\hat{k}) \hat{k}$ and $n_{y}=1$. Then 


$$
\begin{aligned}
{\left[\left(\hat{n}_{x}, \hat{n}_{y}\right) \hat{v}_{u}\left(\begin{array}{l}
\hat{n}_{y} \\
-\hat{n}_{x}
\end{array}\right)\right]=} & {\left[\left(\hat{n}_{x}, \hat{n}_{y}\right) \hat{\jmath}_{0}\left(\begin{array}{l}
\hat{n}_{y} \\
-\hat{n}_{x}
\end{array}\right)\right] } \\
= & f^{\prime \prime}(\hat{k})\left[s_{w^{\prime}}\left(\hat{k} f^{\prime}(\hat{k})-f(\hat{k})-(\hat{k})^{2} f^{\prime \prime}(\hat{k})\right\}\right. \\
& \left.+s_{k}(\hat{k})^{2} f^{\prime \prime}(k)\right] .
\end{aligned}
$$

Therefore condition (E) is satisfied. Q.E.D. 